\title{
REGION INGUINAL: ULTRASONOGRAFIA
}

\section{Dr. José D. Arce V.}

Servicio de Radiología. Clínica Santa María.

Abstract: Anatomy, embryology and ultrasonographic representation of inguinal region are reviewed. Pathology of the groin and their study is discussed with special emphasis in hernias in pediatric patient. Key words: Groin, Groin pathology, Hernia, Small parts, Ultrasound.

Resumen: Se revisa la anatomía, desarrollo embriológico, y la representación ultrasonográfica de la región inguinal. Se discute la patología que la afecta y la necesidad de su exploración con especial referencia a hernias en la edad pediátrica.

Palabras claves: Hernia, Partes blandas, Patología inguinal, Región inguinal, Ultrasonografía.

\section{Introducción}

La región inguinal establece el límite anterior entre la cavidad abdominal y las extremidades. Es una zona anatómica particular ya que por una parte debe permitir el pasaje, hacia las extremidades inferiores y escroto o labios mayores, de estructuras musculares, vasculares, nerviosas y en el hombre de los conductos deferentes, pero a la vez debe impedir que el contenido abdominal se desplace fuera de su cavidad.

Las patologías que la afectan son principalmente hernias congénitas o adquiridas, quistes, varicoceles, patología vascular, inflamatoria y masas. Se agrega en el hombre hidrocele, testículos no descendidos o retráctiles. En una alta proporción el diagnóstico se hará en forma adecuada por el examen clínico no siendo necesarios exámenes de imagen.

Distintos complementos han sido usados para el estudio de esta región ya sea por sospecha de masas, hernias no bien definidas al examen físico o contralaterales a aquellas diagnosticadas clínicamente. Se ha propuesto para su estudio la

Arce JD. Región inguinal: Ultrasonografía. Rev Chil Radiol 2004; 10: 58-69.

Correspondencia: Dr. José D. Arce V.

Avda Santa María 0410. Providencia. Santiago

e-mail: jarce@csm.cl herniografía ${ }^{(1)}$, neumoperitoneografía, laparoscopia ${ }^{(2)}$ y exploración quirúrgica contralateral de rutina. La tomografía computada y la resonancia magnética ${ }^{(3)}$ definen también en forma adecuada la anatomía de la región.

La ultrasonografía (US) constituye una técnica simple de exploración, agregando a sus conocidas ventajas la posibilidad de emular el examen clínico permitiendo en tiempo real una adecuada exploración fisiológica y dinámica del paciente incluyendo la posición de pie.

Revisaremos conceptos embriológicos, anatómicos y el estudio ultrasonográfico normal y patológico de la región inguinal.

\section{Anatomía}

Como en cualquier área a examinar, el conocimiento de la anatomía y su representación en imágenes darán la clave para un adecuado diagnostico, minimizando para el caso del ultrasonido la operador dependencia. Esto es particularmente importante en esta zona de compleja anatomía.

La principal referencia anatómica es el ligamento inguinal, refuerzo aponeurótico del borde libre en la parte inferior de la fascia del músculo oblicuo externo. Este se inserta por arriba y lateral en la espina iliaca anterosuperior y por abajo y medial en el tubérculo del pubis. De esta forma sigue un curso oblicuo descendente desde lateral a medial dejando claramente dos espacios bien definidos. Por encima de su mitad inferior el conducto inguinal y por debajo el canal femoral que a su vez se divide en dos compartimentos o lagunas a) La laguna muscular lateral y superior y b) La laguna vascular medial e inferior $^{(4,5)}$.

I.- Conducto inguinal. Constituye mas que un canal o conducto propiamente tal un trayecto a través del cual las estructuras de la cuerda espermática o el ligamento redondo en la mujer, y sus envolturas emergen en un curso oblicuo desde la cavidad abdominal, partiendo en el anillo inguinal profundo de ubicación lateral y adyacente al peritoneo y vasos epigástricos, extendiéndose hasta el anillo inguinal 
superficial y medial, en contacto con la aponeurosis del oblicuo externo y por encima y medial al tubérculo del pubis (Figura 1 a).

Una referencia anatómica importante en este sitio es la identificación de las estructuras vasculares, especialmente los vasos epigástricos ubicados medial al anillo inguinal profundo pudiendo con ello determinar indirectamente la ubicación de este. De esta forma la relación de una hernia con estos vasos permitirá definir si ella es directa o indirecta (Figura 1c).

II.- Canal femoral. Se extiende desde la inserción superior del músculo sartorio por lateral hasta la del aductor largo por medial, siguiendo un curso oblicuo por debajo del ligamento inguinal y teniendo como piso la bursa iliopectinea y cápsula articular de la cadera por detrás del músculo iliopsoas hacia lateral y el músculo pectíneo por medial. El ligamento iliopectíneo lo divide en dos compartimentos o lagunas (Figura $1 \mathrm{~b}$ ).

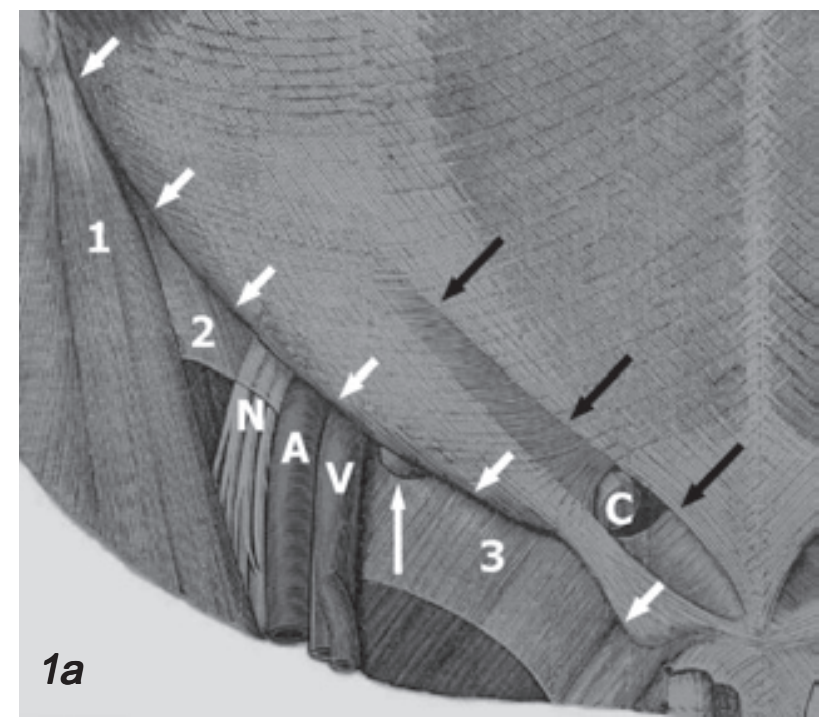

Figura 1 a-c. Anatomía de la región inguinal (a), canal femoral (b) y orificio inguinal profundo derecho (c). El canal femoral en la figura 1 a esta por debajo del ligamento inguinal (flechas blancas cortas). En b el ligamento ileopectíneo separa las lagunas muscular (lateral) y vascular (medial). El orificio inguinal profundo (en c) es lateral a la arteria epigástrica (doble flecha blanca) y a través de el emergen el conducto deferente (flecha corta gruesa) y la arteria testicular (flecha). Canal inguinal (flechas negras largas en a), Espina iliaca antero-superior (flecha negra horizontal en b), Tubérculo del pubis (flecha negra vertical en b). N: Nervio femoral, A: Arteria femoral, $V$ : Vena femoral. Linfonódulo femoral (flecha blanca larga vertical en b) 1: Músculo sartorio, 2: Músculo psoas-iliaco, 3: Músculo pectíneo. C: Cuerda espermática (Modificadas de referencias 4 y 5).
II a.- Laguna muscular. Es un espacio continuo con el retroperitoneo ya que en este sector se funden por delante las aponeurosis del oblicuo mayor y del psoas. A través de ella emergen los músculos psoasiliaco y el nervio femoral. La bursa iliopectinea posterior al músculo y por delante de la cápsula articular de la cadera permite la libre flexo-extensión de ésta.

II b.- Laguna vascular. A través de ella pasan desde el retroperitoneo la arteria femoral que se sitúa lateral y la vena femoral que se ubica medial. Por dentro de ésta última se ubica el ganglio femoral.
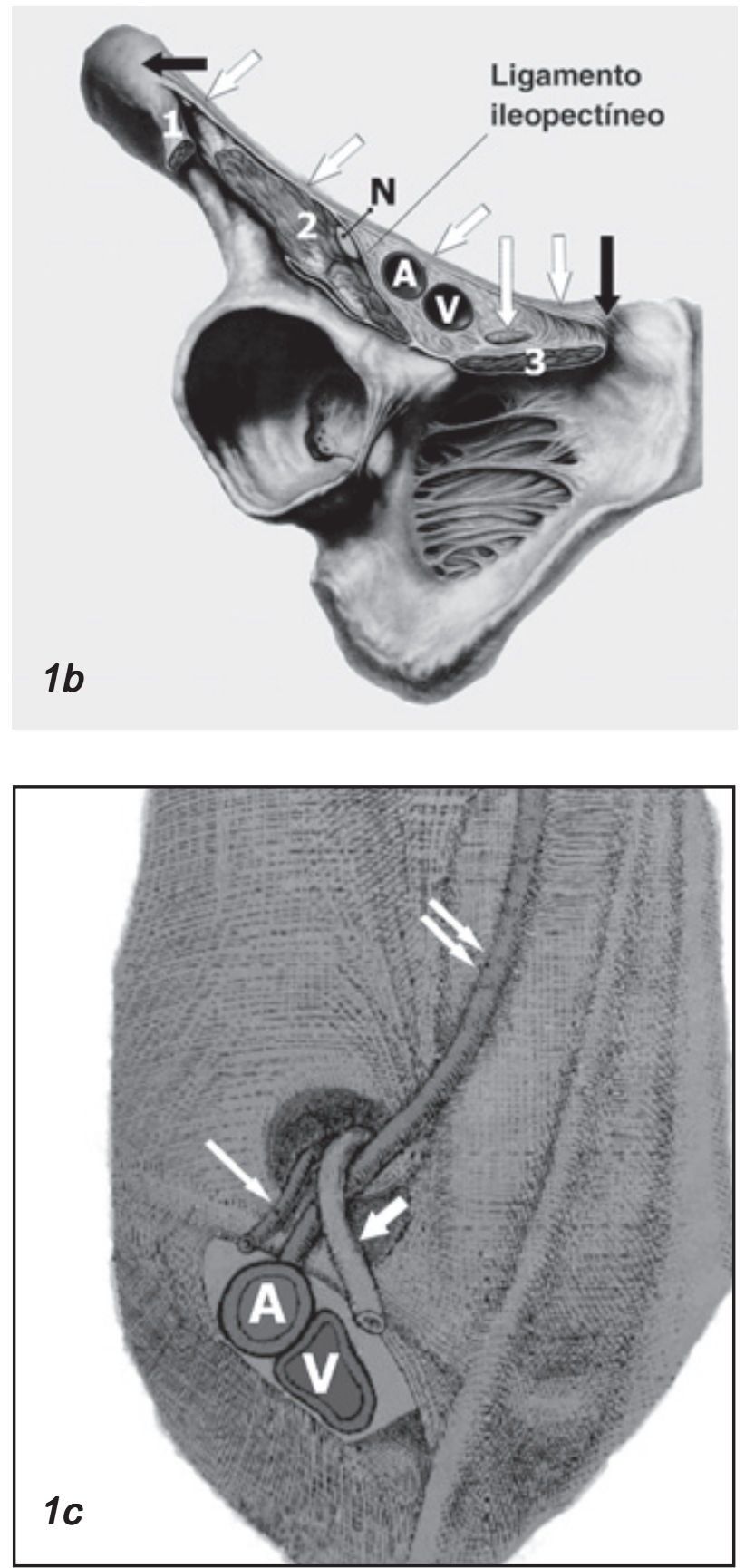


\section{Embriología}

La configuración anatómica descrita se determina en el curso del desarrollo embriológico y esta directamente relacionada a la formación del gubernaculum testis, proceso peritoneo vaginal (PPV) y descenso testicular ${ }^{(6)}$. El canal inguinal seguirá el trayecto de estas estructuras (Figura 2).

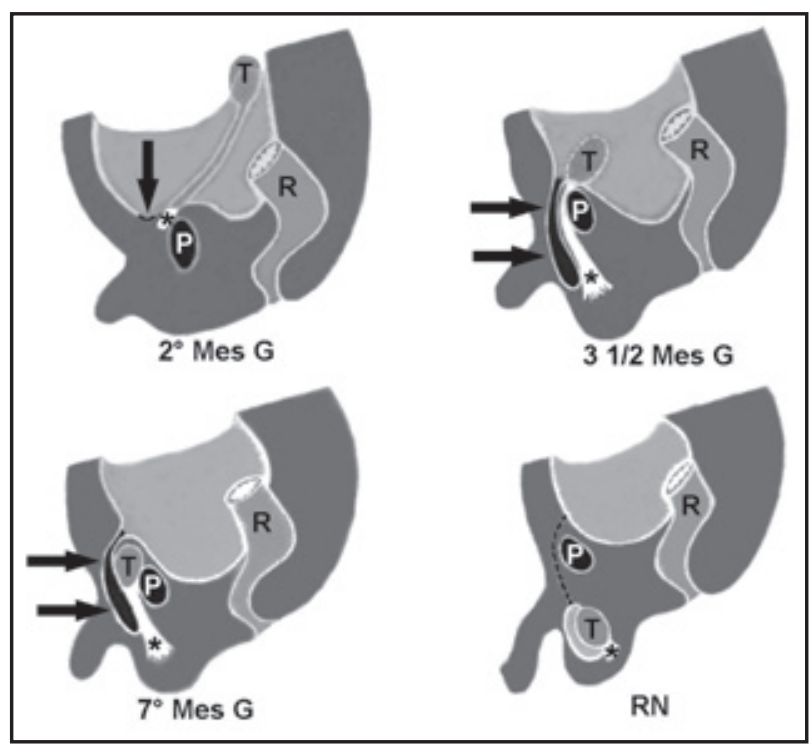

Figura 2. Esquema del desarrollo embriológico del PPV, gubernaculum testis y descenso testicular, a los 2, tres y medio y 7 meses de gestación. El último cuadro corresponde al desarrollo final en periodo de recién nacido. Gubernaculum testis en blanco marcado con asterisco. El origen del PPV se marca con flecha vertical. El PPV se identifica con flechas horizontales. T: Testículo. P: Pubis. $R$ : Recto. (Modificado de referencia 6)

El gubernaculum testis es una cuerda músculofibrosa que esta presente en el feto a partir del segundo mes de vida y se extiende desde el extremo inferior de la gónada hasta debajo de la piel de la región inguinal fetal que posteriormente constituirá la del escroto o labios mayores. Inicialmente presenta un rápido crecimiento siguiendo una posterior involución. En el hombre indica la vía de descenso del testículo a través del canal inguinal al cual ensancha, hasta el escroto. En la mujer su parte media se adhiere al útero impidiendo el descenso del ovario.

EI PPV es una evaginación o divertículo peritoneal formada al tercer mes de vida intrauterina y se origina desde el anillo inguinal profundo por delante y algo medial al gubernaculum. Posterior a él se ubican las estructuras de la cuerda espermática formada por el descenso testicular y que contiene el deferente, estructuras vasculares y nerviosas que acompañan al testículo y que son de origen retroperitoneal, ellas son acompañadas por las fascias y músculos derivados de la pared abdominal. El cierre de este proceso empieza, desde el orificio inguinal profundo, dejando en su extremo distal en el escroto un espacio virtual correspondiente a la cavidad vaginal cuya hoja visceral rodea parcialmente al testículo y epidídimo.

El descenso testicular es un proceso que depende de varios factores no completamente aclarados, entre ellos son importantes factores mecánicos y hormonales. La gónada primitiva formada en el mesodermo intermedio es indiferenciada hasta las 6 a 7 semanas de gestación momento en que se producen los cambios que determinarán el fenotipo sexual. En el hombre se produce la inhibición del desarrollo de los derivados del conducto de Müller. A las 9 semanas hay células de Leydig que producen testosterona la cual estimulara el desarrollo de los derivados del conducto de Wolf. El pasaje de los testículos a través de los canales inguinales se produce durante el tercer trimestre de gestación.

En la mujer el equivalente a la cuerda espermática es el ligamento redondo que alcanza hasta los labios mayores y el PPV es conocido como conducto o divertículo de Nuck.

EI PPV cierra en un alto porcentaje de pacientes después del nacimiento, constituyendo un trayecto fibroso, sin embargo en un número importante de casos lo hace durante el primer año de vida y en un $20 \%$ de los individuos permanece persistente como un espacio virtual durante la vida adulta siendo detectado solo en necropsia, sin haberse manifestado como hernia ${ }^{(5,7)}$.

\section{Anatomía ultrasonográfica}

En US no es posible delimitar el ligamento inguinal como tal ya que como se mencionó es un refuerzo de la aponeurosis del oblicuo mayor y no una estructura claramente definida como otros ligamentos. Sin embargo, es posible localizar las estructuras óseas donde se inserta lo cual es también fácilmente demostrable por el examen clínico. Ello permite proyectar su ubicación y por tanto la del canal inguinal y del canal femoral.

La identificación de los vasos femorales permite por otra parte delimitar la laguna muscular por fuera de ellos y naturalmente la laguna vascular que ellos ocupan. La demostración de los vasos epigástricos permite a la vez definir el orificio inguinal profundo (Figura 3 a).

El orificio inguinal superficial puede ser demostrado por la identificación del tubérculo del pubis por sobre y medial al cual se ubica.

En hombres especialmente niños pequeños con poco tejido adiposo se demuestra mejor la cuerda espermática en su trayecto por el canal inguinal que en ellos es muy corto y más vertical, a diferencia de adultos y niños mayores. En ocasiones 

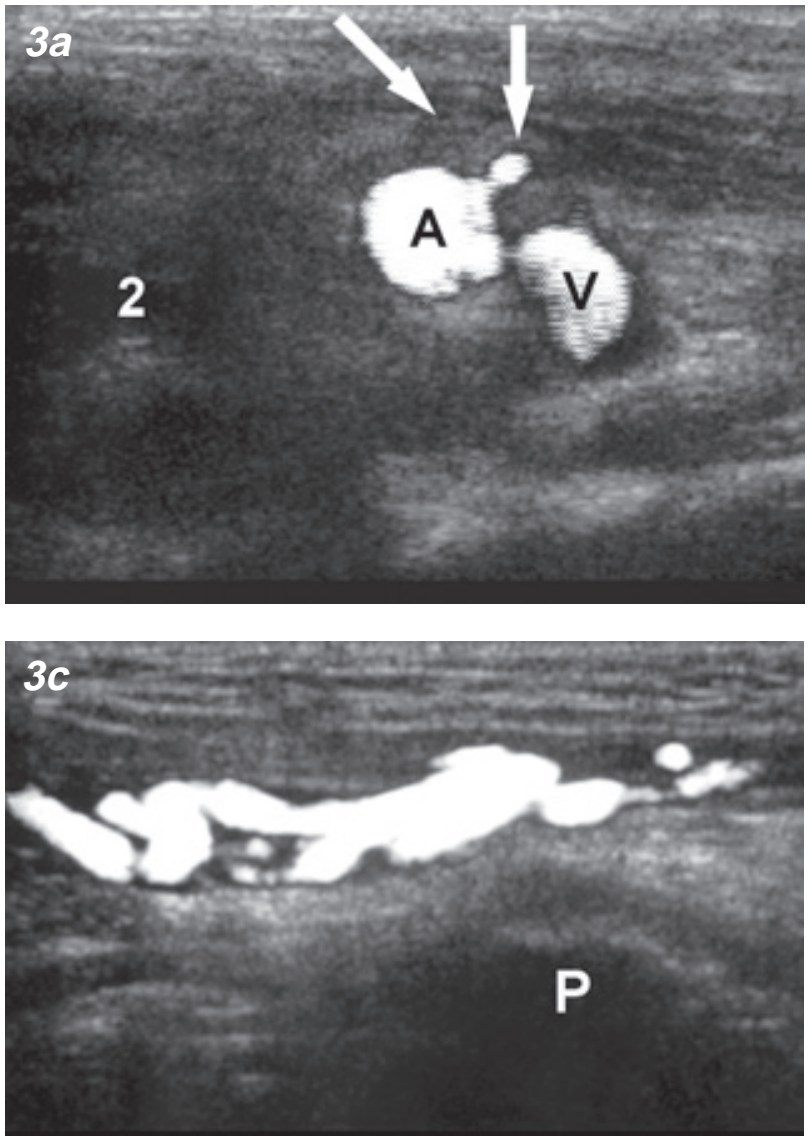
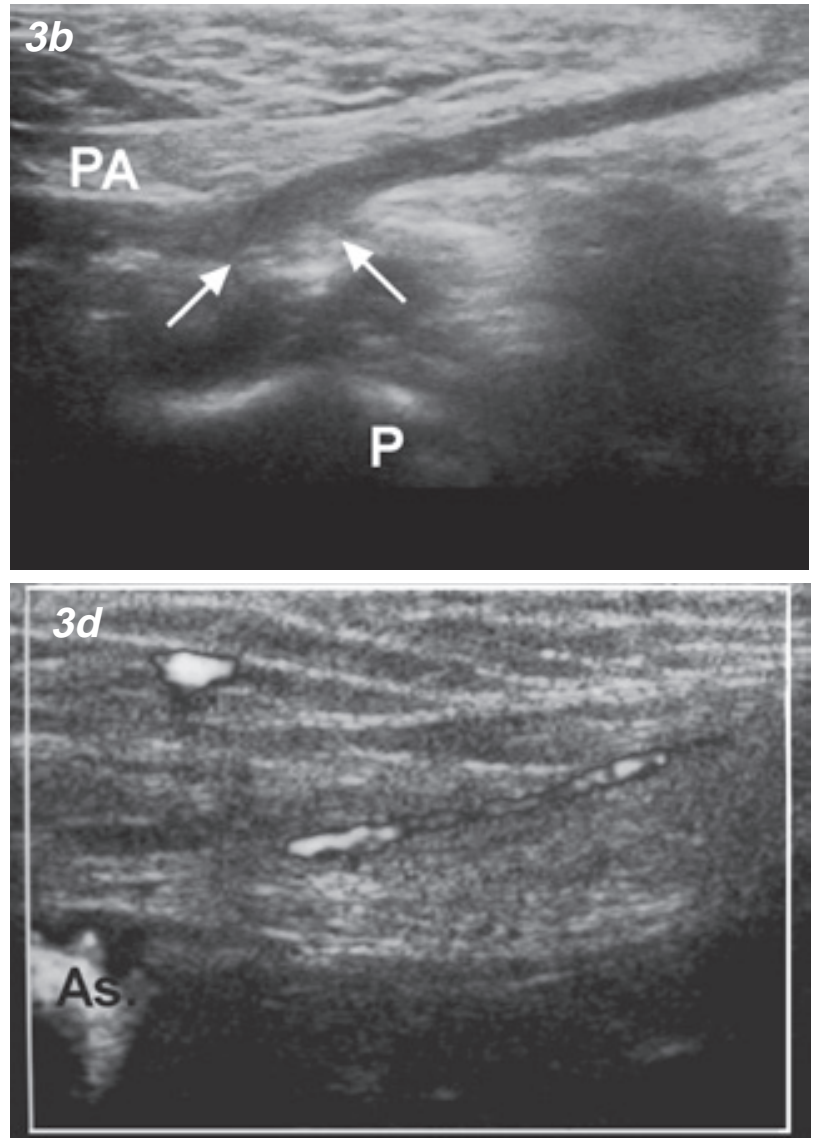

Figura 3 a-d. Anatomía ultrasonográfica del canal inguinal. a: Doppler de amplitud, corte transversal a nivel del orificio inguinal profundo derecho. Se demuestra la arteria (A) y vena (V) femoral definiendo la laguna vascular. La arteria epigástrica inferior se identifica con una flecha corta y el sitio del anillo inguinal profundo con flecha larga. La laguna muscular esta lateral a la arteria. b: Corte semioblicuo en un lactante representando el cordón espermático como una estructura hipoecogenica alargada, se identifica el corto trayecto inguinal con flechas. Doppler de amplitud cortes oblicuos con los vasos marcando el trayecto inguinal en pacientes adultos. Vena espermática en varicocele (c) y Arteria testicular (d).

Músculo psoas-iliaco: 2. PA: Pared abdominal P: Tubérculo del pubis. As.: Detección de asas intestinales con peristalsis por dentro del orificio inguinal profundo.

la identificación de una vena espermática dilatada o bien de la arteria espermática definen su trayecto (Figuras 3 b,c,d).

\section{US inguinal: Método}

El examen se debe efectuar con transductores lineales de $7 \mathrm{MHz}$ o de mayor frecuencia. El uso de Doppler color o de amplitud es indispensable para la identificación de las estructuras vasculares que servirán de referencia anatómica.

Al comenzar con cortes transversales resulta más fácil ubicar los vasos y delimitar los diferentes compartimentos, posteriormente cortes oblicuos o más verticales en lactantes permitirán delimitar el trayecto inguinal.

Identificados los reparos anatómicos óseos y vasculares y definidos los compartimentos, en el caso de la existencia de patología, se procede a ubicarlos en ellos.

El paciente debe ser explorado en posición supina y si ninguna patología es demostrada se debe continuar el examen en posición erecta. En ambas situaciones se debe pedir al paciente que efectué maniobra de Valsalva. En caso de preescolares o lactantes la posición erecta y la maniobra de Valsalva puede ser ayudada por los padres y efectuando compresión abdominal. El llanto a pesar de ser molesto es una muy buena maniobra para aumentar la presión abdominal.

Una adecuada maniobra de Valsalva puede ser monitorizada por el aumento de calibre de la vena femoral.

\section{US inguinal indicaciones}

Un buen examen clínico en la mayoría de los casos permitirá un fácil diagnóstico de patologías que afectan esta región, en particular la presencia de hernias. En este último caso la utilidad del examen radicara en la investigación de una hernia contralateral lo que ayudara a tomar una conducta 
terapéutica adecuada para cada paciente en particular.

En casos de hernias se puede reconocer el tipo y diferenciarlas en directas, indirectas o crurales. Además se puede caracterizar su contenido.

Las masas inguinales indeterminadas se pueden diferenciar en sólidas o quísticas, en casos de gónadas herniadas es posible reconocerlas como masculinas o femeninas, también se puede reconocer estructuras anatómicas normales aumentadas de tamaños como linfonódulos. La ubicación de masas en los diferentes compartimentos permite establecer su origen que a veces puede ser abdominal o retroperitoneal.

En casos de hidroceles en niños podemos investigar la amplitud de su comunicación lo que refleja la amplitud del canal inguinal, por tanto una potencial hernia.

Posterior a la cirugía la US permite estudiar una eventual complicación local o a nivel del testículo, especialmente compromiso isquémico.

\section{A.- Patología de la laguna muscular}

Aun cuando pueden ser confundidas al examen clínico con patología del canal inguinal, su exacto reconocimiento anatómico es importante, ya que en algunos casos puede reflejar una patología intraabdominal retroperitoneal que emerge hacia la superficie en este sector por la continuidad que da el trayecto del músculo psoas-iliaco en su recorrido. En particular procesos infecciosos retroperitoneales primarios o de malformaciones congénitas afectan este sector, también patologías propias del músculo psoas iliaco o de su vecindad (Figura 4).

Patología de la articulación coxofemoral o complicaciones post-quirúrgicas se pueden manifestar en esta región ${ }^{(8)}$.

\section{B.- Patología de la laguna vascular}

Hernias crurales, patología vascular como pseudoaneurismas y del linfonódulo femoral afectan este compartimiento. La identificación directa de los vasos al estudio Doppler o de masas en su inmediata vecindad las hace fácilmente identificables.
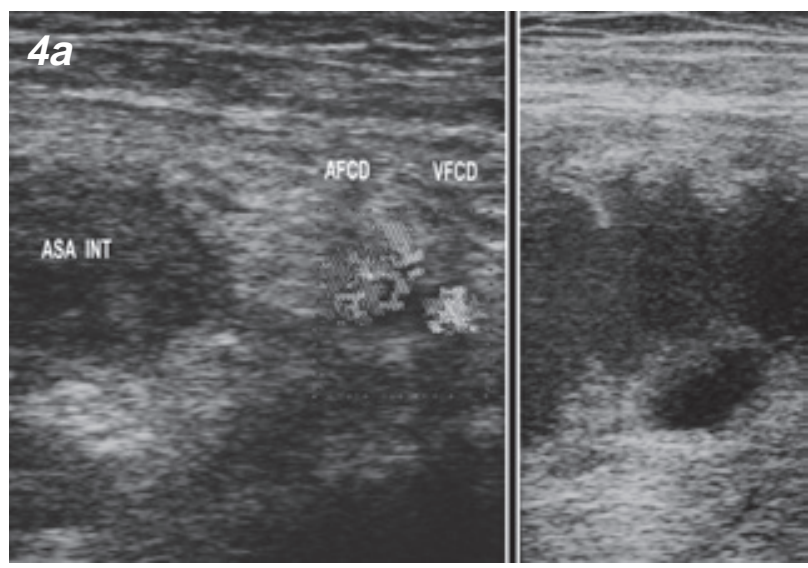
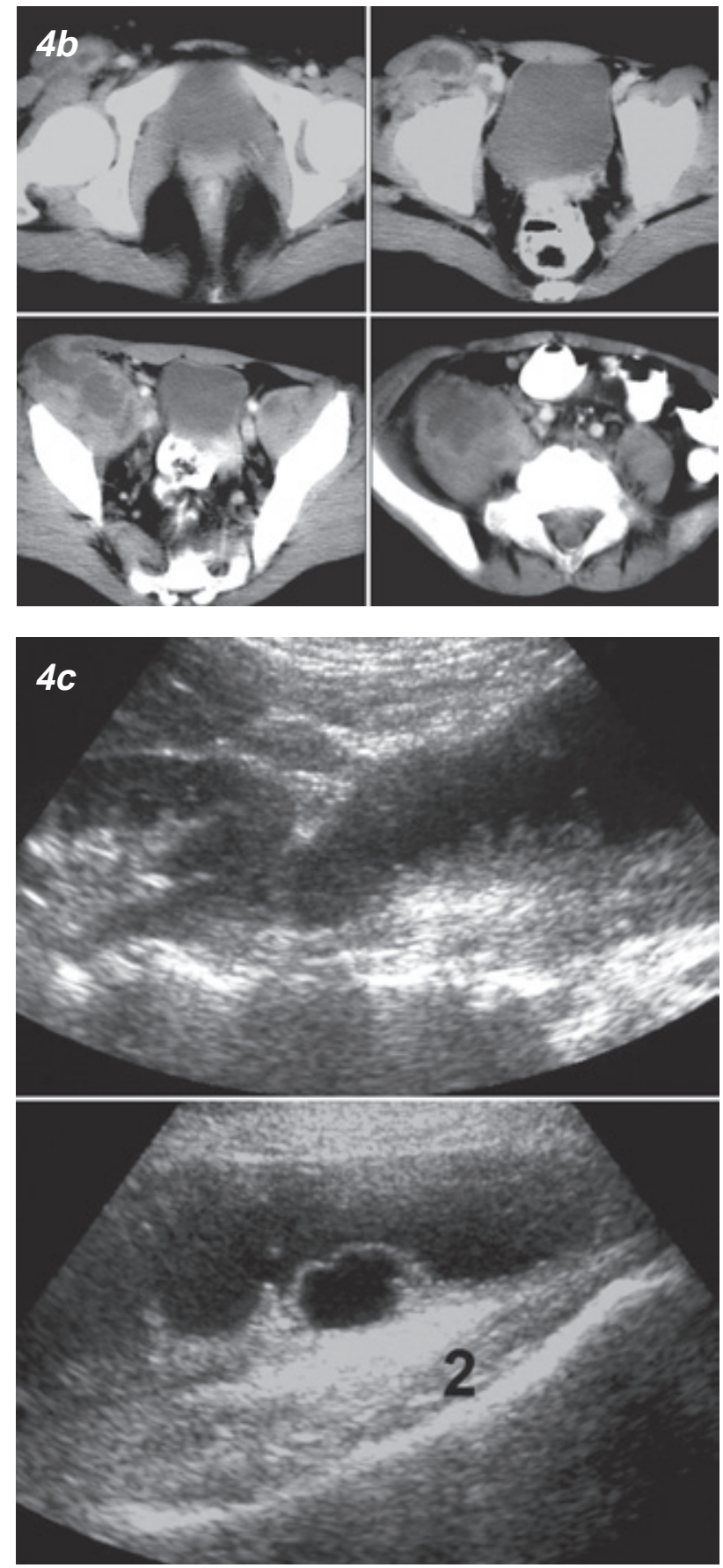

Figura 4 a-c. Linfangioma retroperitoneal derecho infectado, en una niña de 11 años. Aumento de volumen inguinal interpretado como hernia. Obsérvese en a, que los reparos anatómicos fueron claramente identificados, y debió haberse hecho el diagnóstico de patología en la laguna muscular. a: US en cortes transversal (izquierda) y longitudinal (derecha) mostrando la lesión lateral a la arteria femoral. b: TC que demuestra la colección retroperitoneal y su extensión hacia la laguna muscular. c: US posterior a TC. Cortes longitudinales en el trayecto del psoas. Se identifica la colección en el abdomen a partir del polo inferior del riñón derecho. Un adecuado conocimiento anatómico pudo haber extendido la exploración inicial a este sector. AFCD: Arteria femoral. VFCD: vena femoral. Asa int: Marca incorrecta del linfangioma. 2: Músculo Psoas. 
Las hernias en este sector llamadas crurales o femorales se identifican medial a la vena femoral y dado la estrechez del canal pueden complicarse fácilmente (Figura 5).
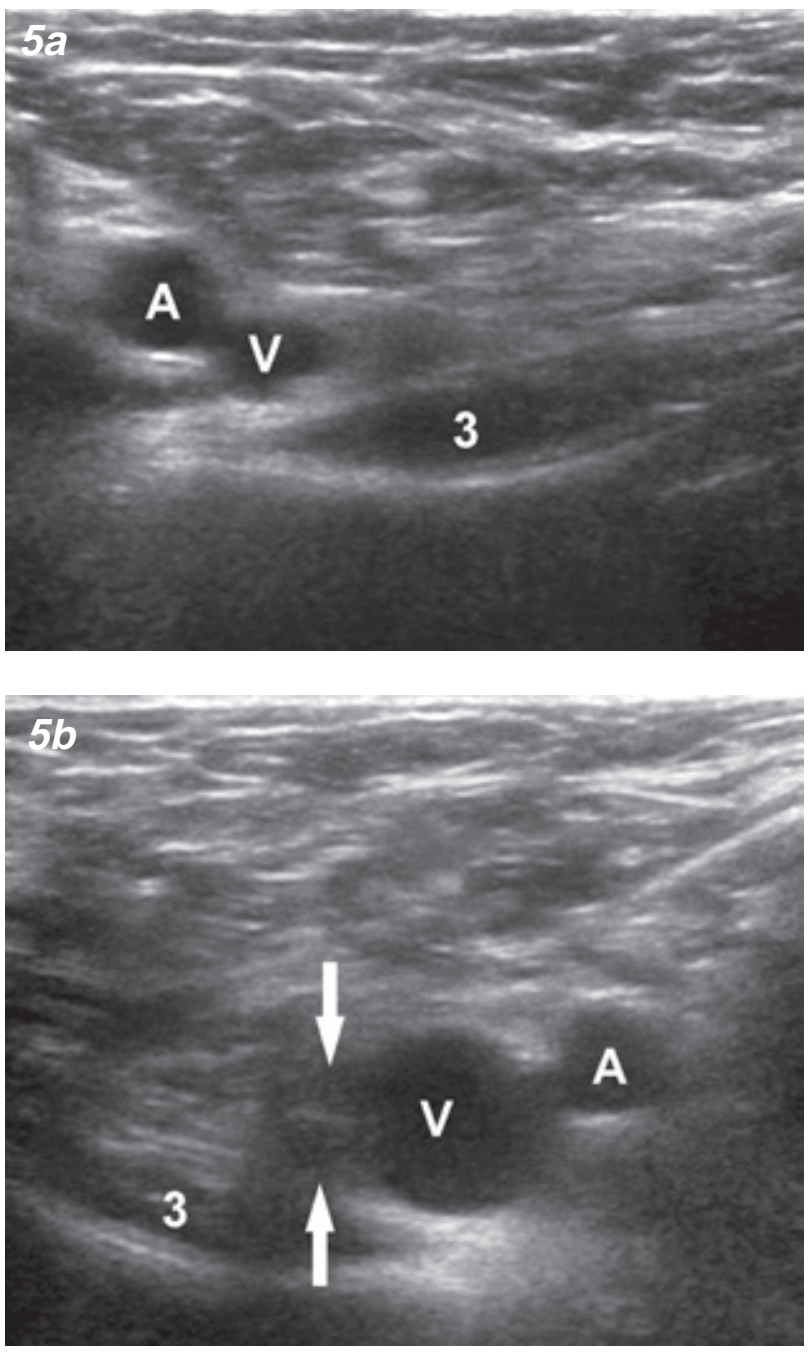

Figura 5 a,b. Hernia crural o femoral izquierda. Cortes transversales, lado derecho normal (a) e izquierdo (b). La hernia solo se identifico en posición de pie y con maniobras de Valsalva medial a la vena (flechas). A: Arteria V: Vena. 3: Músculo pectíneo.

\section{C.- Patología del canal inguinal}

Las hernias y patologías asociadas como el hidrocele, quistes del cordón y testículos no descendidos afectan esta región. El varicocele tanto femenino como masculino son también patologías de este sitio anatómico.

\section{1.- Hernia inguinal}

Una primera aproximación a considerar es el concepto de hernia inguinal. Para algunos la presencia de un PPV persistente es considerada como tal, sin embargo es sabido que en autopsias un porcentaje de pacientes lo tiene, sin que durante su vida se haya manifestado clínicamente como hernia. Por tanto el concepto considerado en esta revisión es la presencia de contenido abdominal o líquido en el canal inguinal.

Las hernias inguinales pueden ser directas o indirectas según hagan prominencia por una zona débil de la fascia transversal o a través del PPV persistente respectivamente. La identificación de la arteria epigástrica inferior permite caracterizarlas ya que las directas se ubican medial a esta y las indirectas lateral a ella (Figura 6).

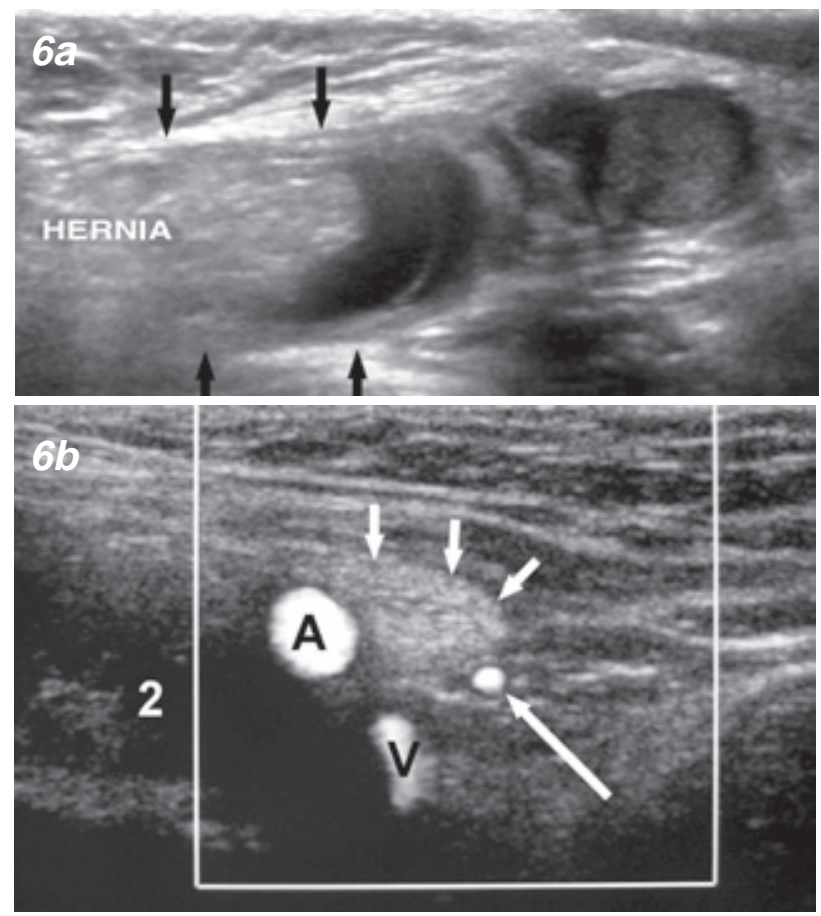

Figura 6 a,b. Hernia inguinal indirecta con contenido de epiplón. a: Corte oblicuo demostrando la hernia con epiplón. b: US Doppler de amplitud, corte transversal demostrando la hernia (flechas cortas) lateral a la arteria epigástrica inferior (flecha larga). A: Arteria femoral V: vena femoral. 2: Músculo psoas-iliaco.

En varones la hernia indirecta es frecuente y la exploración ultrasonográfica estará dirigida a caracterizar su contenido en el lado diagnosticado clínicamente y a pesquisar una hernia contralateral. En general el contenido herniario es epiplón (Figura 7) o asas intestinales (Figura 8) que son fácilmente reconocidas por su peristalsis en tiempo real. Otros estructuras como vejiga, apéndice, bazo, tejido suprarrenal o catéteres derivativos pueden ocupar la hernia (Figura 9). En mujeres ovario, útero y trompas pueden estar presentes en el saco herniario.

La hernia inguinal indirecta se define en US por un anillo inguinal profundo mayor de $4 \mathrm{mms}$., la presencia de liquido en el proceso peritoneo vaginal y naturalmente la presencia de contenido abdominal en el trayecto inguinal ${ }^{(9)}$. 

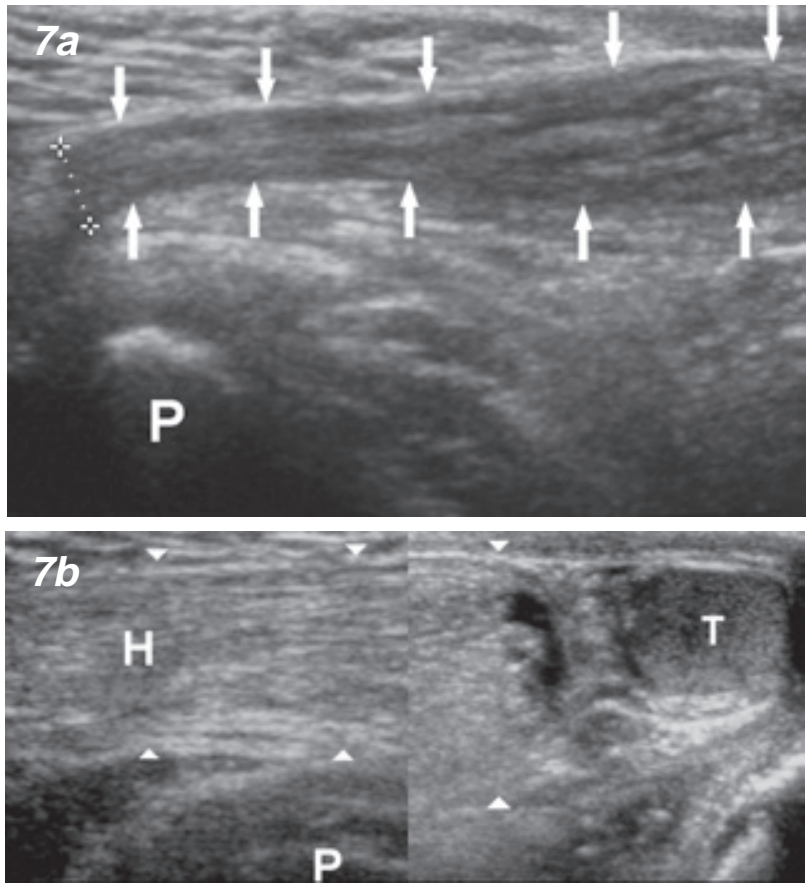

Figura 7 a,b. Hernia inguinal indirecta con contenido de epiplón. Se demuestra la importancia de la exploración de pie. El decúbito (a) solo permite detectar el saco herniario (flechas). b: Imagen compuesta en posición de pie. La hernia es identificada con una $\mathrm{H}$ y rodeada de punta de flechas. P: Tubérculo del pubis. T: Testículo.

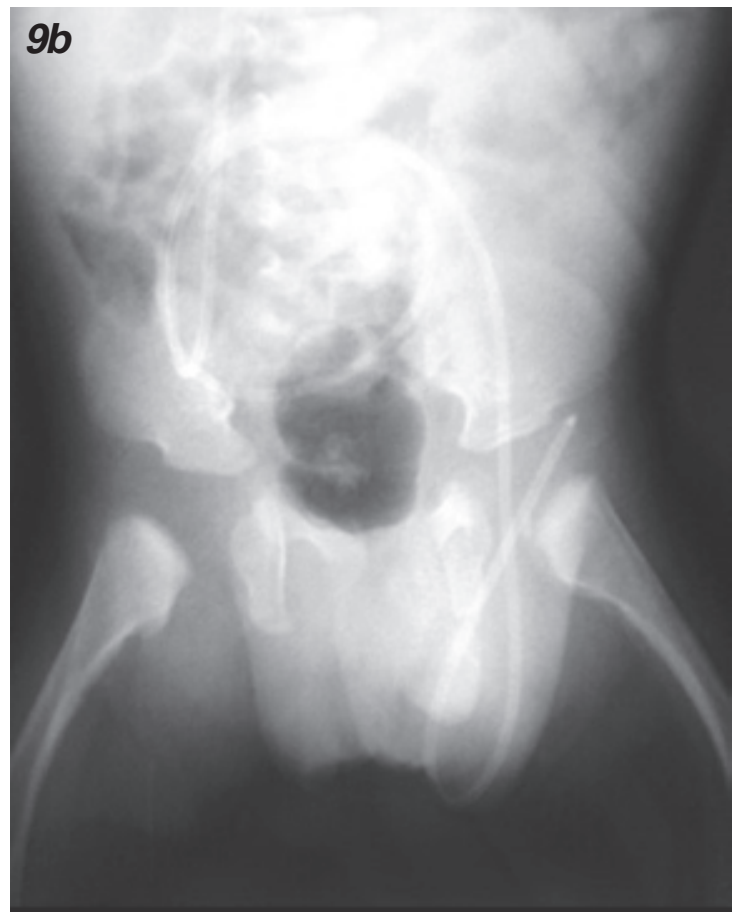

Figura 9 a-c.

Hernia inguinal con catéter de válvula cerebroperitoneal. a: US imagen compuesta de cortes longitudinales demostrando el catéter como líneas ecogénicas paralelas. Radiografías simples AP (b) y lateral (c) identificando el catéter radioopaco.
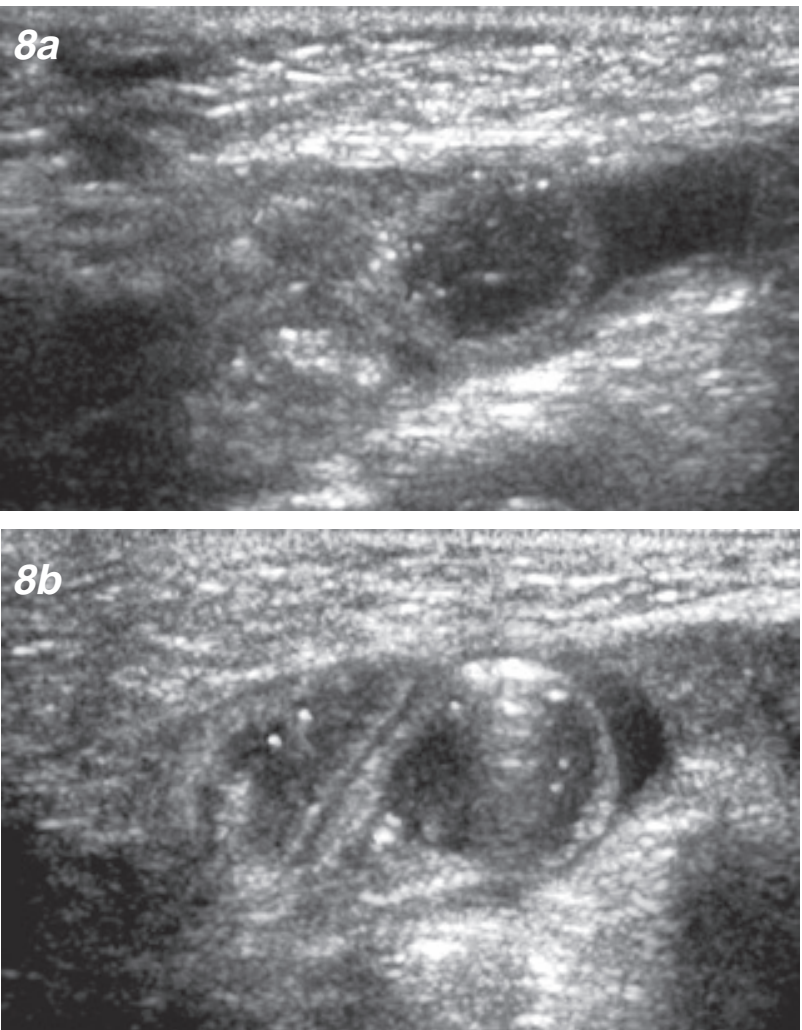

Figura 8 a,b. Hernia inguinal con contenido de asa intestinales. Cambio de morfología del contenido herniario por la peristalsis.
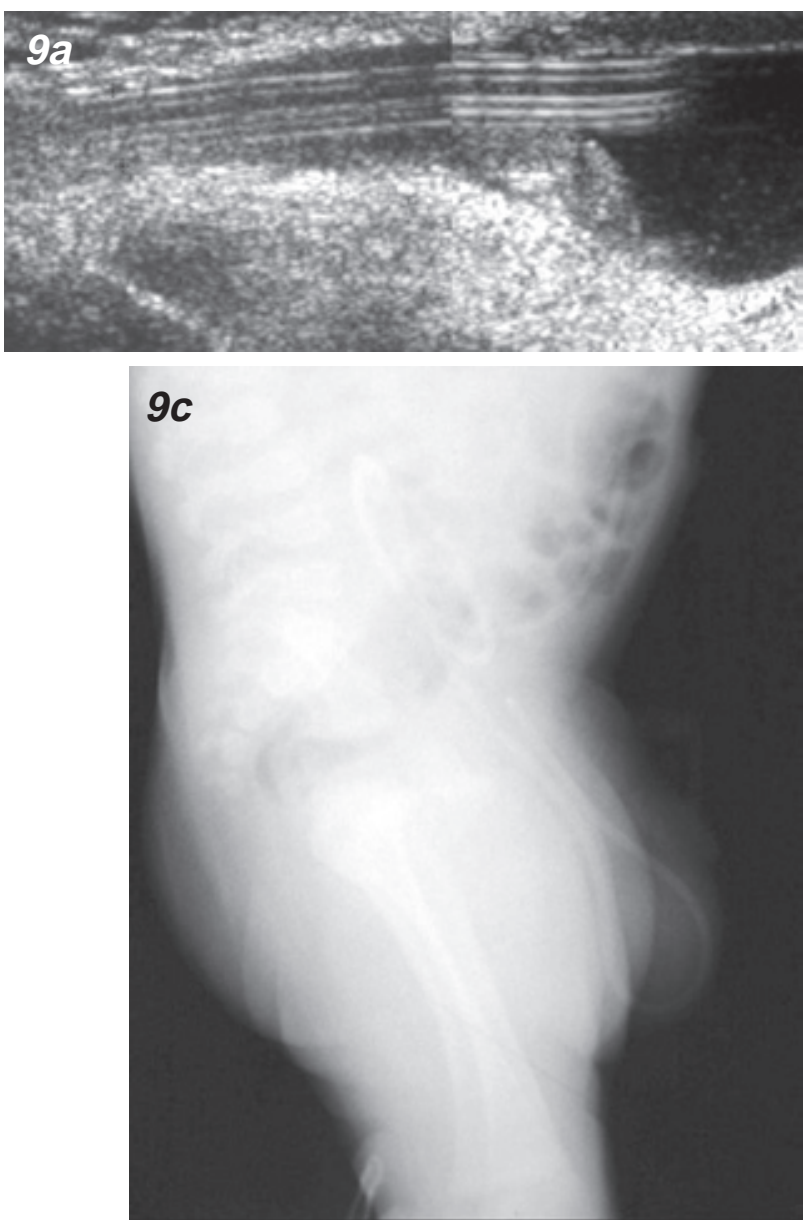


\section{Hernia contralateral}

El diagnóstico clínico de hernia unilateral es fácil existiendo algunas limitaciones en pacientes obesos o en algunos casos de hernias reductibles pequeñas no evidentes al examen habitual. La indicación quirúrgica es indiscutible, sin embargo la posibilidad de una hernia oculta en el lado opuesto existe. La exploración quirúrgica contralateral de rutina ha generado controversia que se extiende desde la década del 50 y de la cual aun no hay acuerdo absoluto. Se discute incluso si la demostración de un PPV persistente por si solo debe ser considerado como una hernia.

Una encuesta realizada a miembros de la sección quirúrgica de la Academia Americana de Pediatría demostró que un $65 \%$ de los cirujanos que respondieron exploraban de rutina el lado opuesto en hombres menores de 2 años y un $84 \%$ el de mujeres hasta los 4 años ${ }^{(10)}$.

La cirugía contralateral no fundamentada puede ser difícil de explicar al paciente o padres, en el caso de niños, y en tiempo de juicios a la acción médica resultará más difícil explicar una eventual complicación.

Los partidarios de explorar ambos lados argumentan que con esta conducta evitaran la posibilidad de una hernia complicada contralateral, un nuevo riesgo anestésico y el costo de una segunda hospitalización. Agregando que quitarían el temor de los pacientes o padres de la eventualidad de una segunda intervención.

Los opositores por su parte argumentan que de cada 5 intervenciones 4 serían innecesarias ya que el riesgo de un PPV abierto y por tanto el riesgo de herniación es de un $20 \%$ en población asintomática. Además argumentan la posibilidad de daño del conducto deferente con consecuencia de esterilidad en 1 a $2 \%$ de los casos o bien la posibilidad de un daño testicular en 2 a $13 \%$ de los $\operatorname{casos}^{(7)}$.

Diversos criterios se han usado para argumentar la exploración quirúrgica rutinaria contralateral como lo son edad, sexo, lado de la hernia, prematurez y estrangulación ${ }^{(7)}$. De acuerdo a Bock y Sobye en un seguimiento de 27 a 36 años en 174 pacientes con hernia unilateral solo $15 \%$ desarrollo hernia en el lado opuesto(11). Otro estudio reciente con un seguimiento entre 5 a 10 años demostró para niños operados antes del primer año de vida una incidencia promedio de $7.7 \%$ de hernia contralateral sin diferencia significativa para sexo, lado de la hernia o prematurez. En ninguno de los casos hubo estrangulación ${ }^{(7)}$.

\section{2.- Hidrocele comunicante}

Este tipo de hidrocele tiene una clara expresión clínica manifestada por el aumento de tamaño durante la actividad diaria y puede alcanzar hacía distal hasta el cordón o escroto. En niños en general todos los hidroceles son resultado de un PPV persistente o retardo del cierre. Lo importante en estos casos es pesquisar la eventual coexistencia de hernia y la amplitud del orificio inguinal profundo. La presencia del testículo en su posición normal también debe ser investigada.

El hidrocele escrotal o funicular son de fácil diagnostico clínico y ultrasonográfico. La mayor atención en el estudio ultrasonográfico debe ser dirigida a demostrar la continuidad del contenido líquido hacia el trayecto inguinal (Figura 10). Maniobras de compresión sobre el extremo distal del hidrocele permiten desplazar el contenido líquido, que puede identificarse en el canal inguinal ensanchado. La exploración del paciente en posición erecta permite también la demostración de líquido en el canal y en algunos casos contenido herniario.
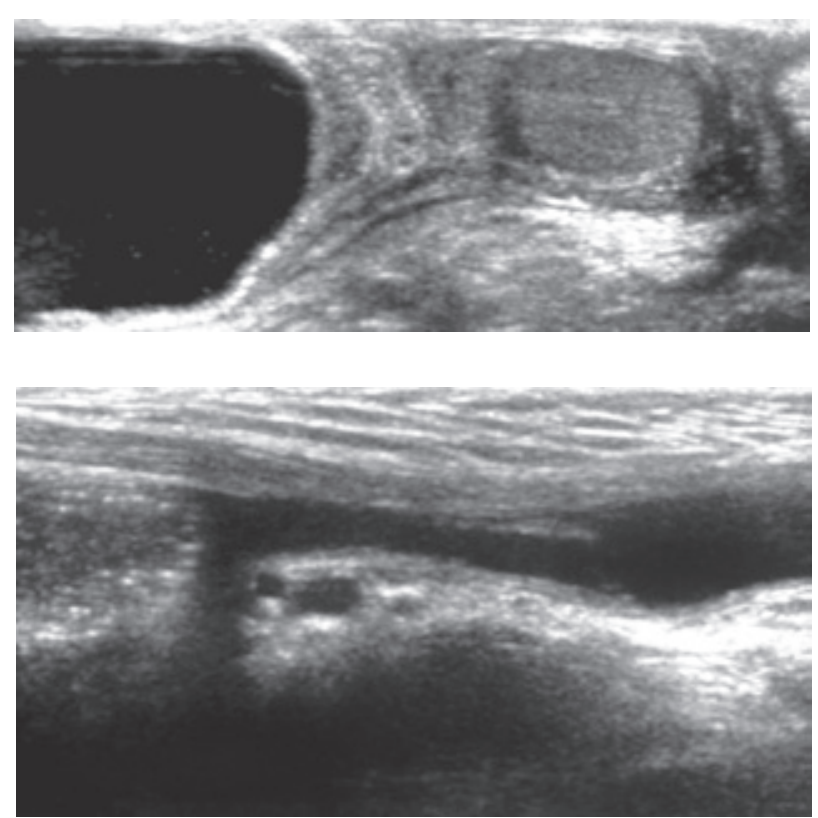

Figura 10 a,b. Hidrocele funicular comunicante. a: Corte longitudinal sobre el testículo. b: La compresión sobre el líquido lo desplaza hacia el canal inguinal.

Un hidrocele comunicante puede manifestarse tardíamente por la existencia de epiplón que ocluye el orificio inguinal profundo(12).

A veces el hidrocele puede extenderse hacia el abdomen constituyendo el tipo abdomino-escrotal que comprende entre el 1.25 a $3.1 \%$ del total de los hidroceles $^{(13)}$ (Figura 11).

\section{3.- Testículo no descendido}

El testículo no descendido es frecuente en prematuros y ocurre en un $3 \%$ de los recién nacidos 

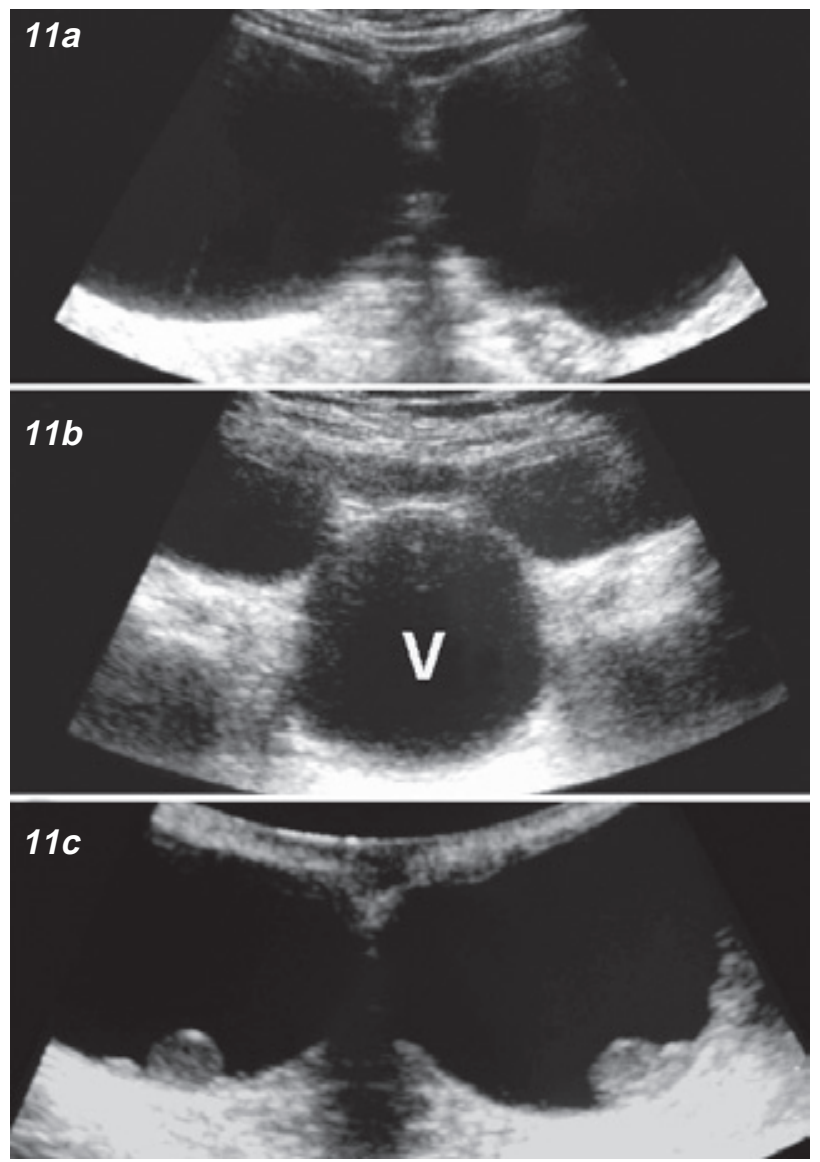

Figura 11 a-c. Hidrocelele abdominoescrotal bilateral. Cortes transversales efectuados a nivel abdominal supravesical (a), pelviano (b) y escrotal (c). V: Vejiga.

de termino. Además del descenso intrauterino un porcentaje lo hace durante el primer año de vida quedando una tasa definitiva de un $1 \%$ de testículos no descendidos después de este periodo. De ellos un $20 \%$ son no palpables ${ }^{(14,15)}$.

Se pueden clasificar los testículos no descendidos en palpables y no palpables. En los últimos dependiendo de la conformación del orificio inguinal profundo se reconocen las variantes anillo cerrado y anillo abierto. En algunos casos se ubican en sitios ectópicos por fuera del lugar de descenso normal.

En la mayoría de los casos se asocian a anomalías del epidídimo y hernias inguinales indirectas ya que en un $90 \%$ de los casos se encuentra un PPV persistente.

Algunas publicaciones de la literatura norteamericana dan un bajo rendimiento para el US en cuanto a pesquisa de testículos no descendidos comparado a testículos palpados en examen clínico efectuado por especialistas. La falla del US ocurre para ellos en un $61 \%$ de los casos $^{(16)}$. Nuestra experiencia aun cuando no tabulada es diferente y probablemente ello este relacionado a la diferente forma de enfocar el examen ultrasonográfico.
La metódica de examen es igual al de hernias siendo objetivado el testículo con su clásica morfología y ecogenicidad (Figura 12) o en algunos casos, con signos de atrofia en diferentes grados. Un hallazgo interesante es la identificación del testículo en posición ectópica alta entre las diferentes capas de la pared abdominal en una hernia interparietal sitio que debe ser investigado si no es encontrado en el trayecto del canal o del cordón (Figura 13).

Es frecuente en niños encontrar testículos en posición alta, que corresponden en un alto porcentaje de casos a testículos retráctiles o en ascensor. Nuevamente la exploración efectuando maniobras para descenderlo y la posición erecta permite la diferenciación, ya que el testículo retráctil se puede descender al escroto.

\section{4.- Hernia y patología inguinal en el genero femenino}

Del total de hernias inguinales indirectas las que afectan al genero femenino comprenden un 13$23 \%{ }^{(17)}$ y entre el $15-45 \%$ son no reductibles ${ }^{(18)}$. El contenido ovárico es frecuente y se presentan como masas de labios mayores, constituyendo hernias indirectas por deslizamiento ya que van acompañadas por mesenterio (Figura 14). A veces las trompas y útero especialmente cuando es didelfo pueden acompañarlo. Los ovarios son fácilmente reconocibles por la presencia de folículos. Esto es particularmente importante para ayudar a establecer la asignación de sexo. A veces en niños con una gran hipospadia puede asignarse en forma equivoca el sexo femenino y en ellos se puede reconocer la gónada masculina carente de folículos en los supuestos labios mayores.

Los ovarios herniados al quedar atrapados en la hernia están expuestos a sufrir torsión e infarto(18).

Venas dilatadas en los labios mayores se puede reconocer en mujeres especialmente durante el embarazo y corresponde al llamado varicocele femenino externo que al igual que en el hombre se hace más evidente con maniobras de Valsalva y en posición de pie (Figura 15). Estas dilataciones venosas, de las ramas profundas de los labios mayores, se asocian a varicocele pelviano que produce el síndrome de congestión pelviana causa importante de dolor crónico ${ }^{(19)}$. Aun cuando esta patología es multifactorial un factor importante es el aumento de flujo que se produce en las venas ováricas durante el embarazo y que alcanza hasta 60 veces el flujo normal(20).

Al igual que en el hombre la presencia de líquido en el trayecto de un PPV persistente o conducto de Nuck determinara un hidrocele o un quiste (Figura 16). La eventualidad de una hernia asociada debe ser considerada en estos casos. 


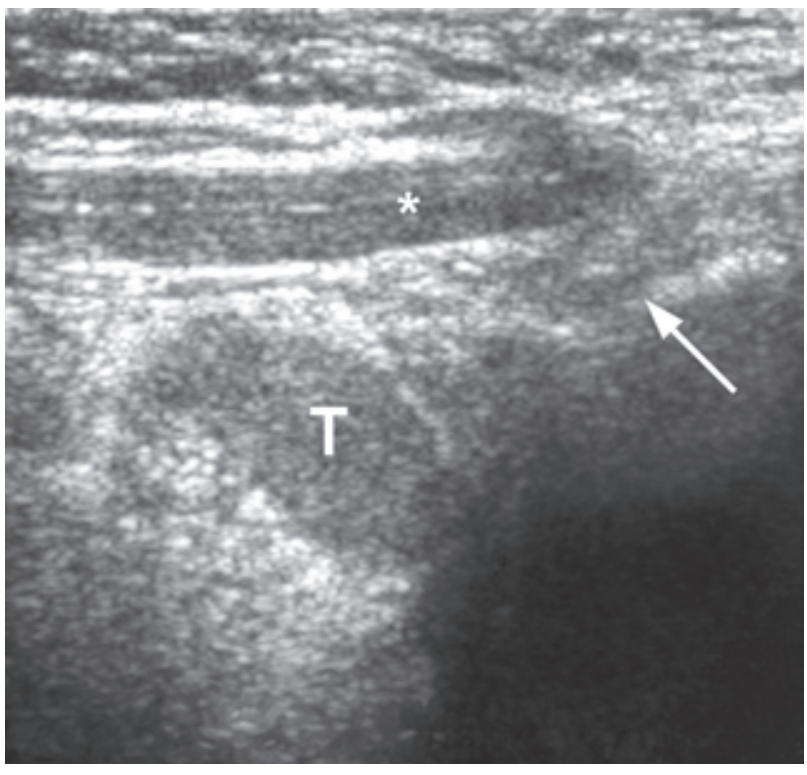

Figura 12. Testículo no descendido intraabdominal. Corte oblicuo efectuado con el paciente en posición de pie. La pared abdominal se marca con asterisco y el canal inguinal con flecha. T: Testículo.

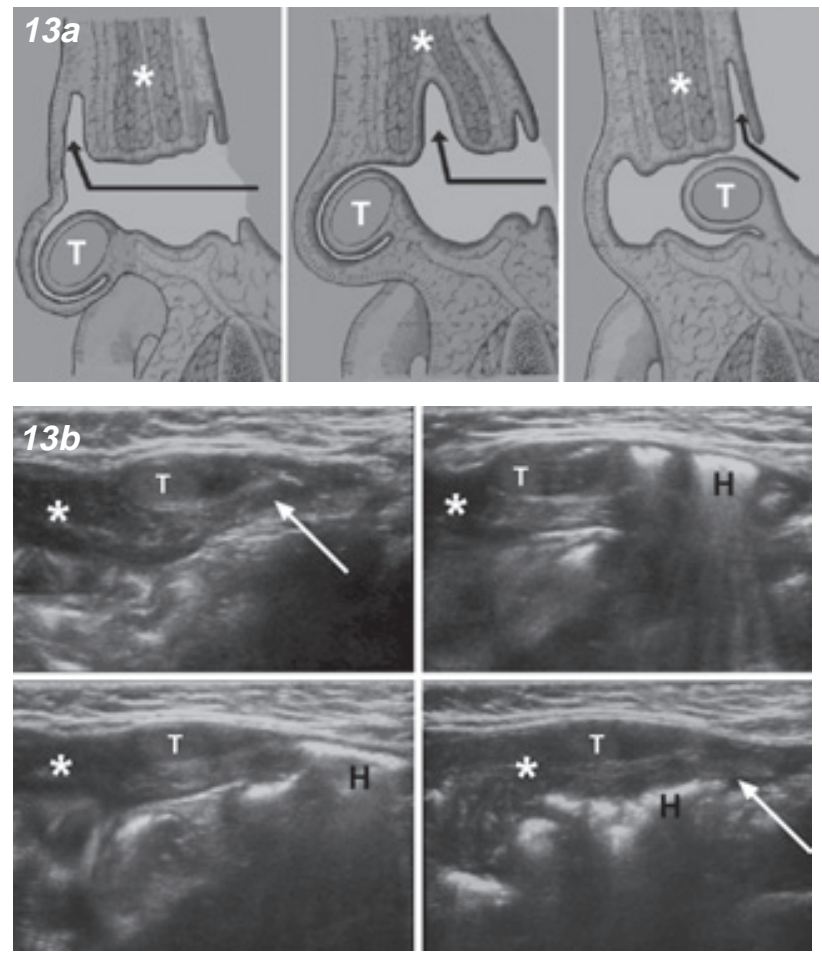

Figura 13 a,b. Testículo ectópico en hernia interparietal. a: Esquema demostrando los distintos tipos de hernia interparietal: superficial, intersticial y preperitoneal respectivamente. b: US demostrando una hernia con testículo ectópico (T) y asas que entran y salen (H). La pared abdominal se marca con asteriscos y el canal inguinal con flechas.
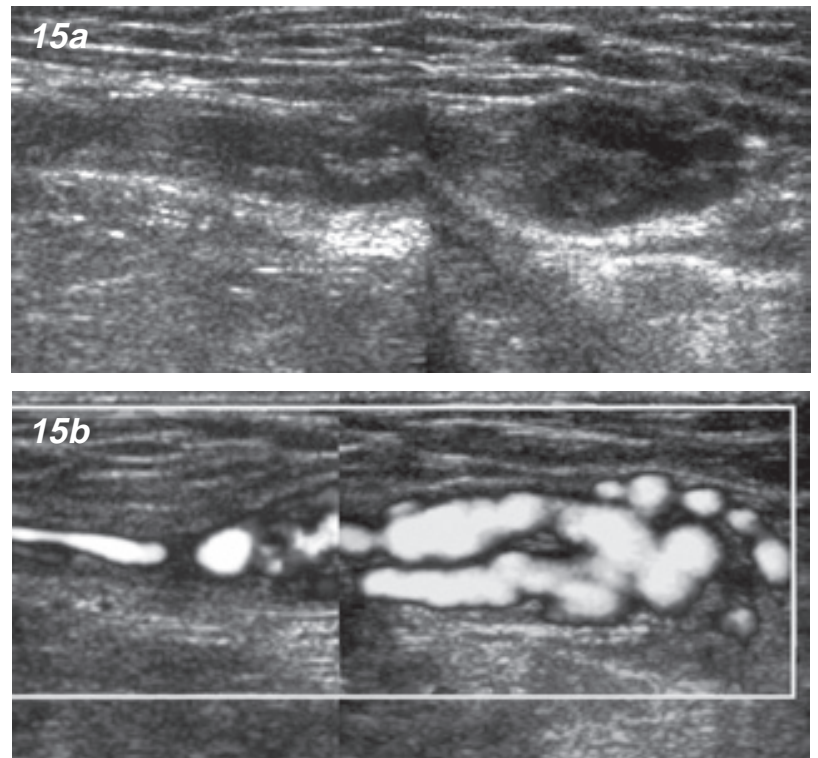

Figura 15 a,b. Varicocele femenino mujer de 28 años en su octavo mes de embarazo. Imagen compuesta en modo $B$ (a) y Doppler de amplitud (b) demostrando las dilataciones venosas en labios mayores especialmente evidentes con maniobras de Valsalva.

Figura 14 a,b. Hernia con contenido ovárico en modo $B$ (a) y Doppler color (b) demostrando el trayecto de los vasos ováricos a través del canal inguinal. 


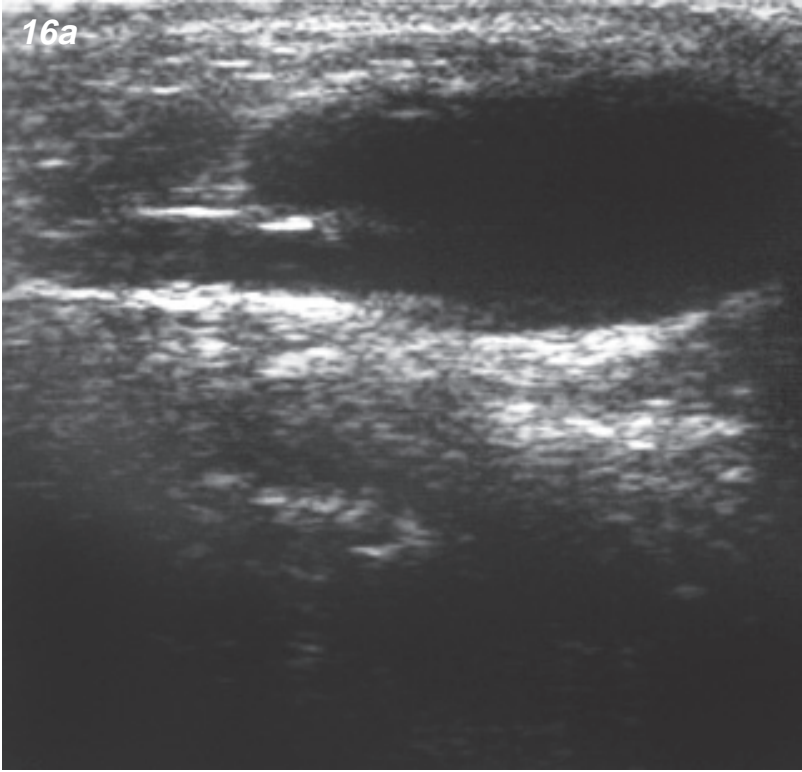

Figura 16 a,b. Formación quística derecha del conducto de Nuck en una mujer de 16 años operada previamente con el diagnóstico de linfangioma de labios mayores. a: US corte longitudinal. b: Quistografía efectuada por punción directa. En ambos casos obsérvese la prolongación superior de la formación quística en relación a un un conducto de Nuck persistente.

\section{Discusión}

La hernia inguinal es una patología quirúrgica habitual y en el niño el tipo indirecto es el mas frecuente $^{(21)}$. La cirugía además de eliminar las molestias previene una eventual estrangulación del contenido herniario y sus complicaciones.

El examen físico permite un adecuado diagnóstico aun cuando comparado con la exploración laparoscópica pierde algunas hernias contralaterales pequeñas y en algunos casos puede determinar falsos positivos por la presencia de masas inguinales diferentes de hernias como ocurre con lipomas preperitoneales o del cordón $^{(3)}$. En US la diferenciación de esta última situación es fácil ya que tanto el orificio inguinal profundo como el canal inguinal aumentan su tamaño con maniobras en caso de hernias, hecho que no ocurre con el lipoma. Otra diferenciación importante es con hidrocele especialmente en niños menores de 4 meses donde una eventual remisión de este último debe ser esperada.

Para fundamentar la exploración quirúrgica del lado opuesto a una hernia unilateral diversos procedimientos han sido empleados, como el uso durante la cirugía del dilatador de colédoco, la herniografía, el neumoperitoneo intraoperatorio y la laparoscopía.

Desde los comienzos de la década del $90^{(8,22)}$ la US ofrece una alternativa valida con buen rendimiento al ser comparada con laparoscopía y hallazgos quirúrgicos y en varios centros ha cambiado la práctica de exploración quirúrgica contralateral de rutina, dando fundamentos a esta cuando es necesaria. Su seguridad diagnostica comparada con cirugía es de $92 \%{ }^{(22)}$ y su sensibilidad comparada con esta y laparoscopia es de $95 \%$. En la serie de Chen y col. se demostró para la detección de hernia una seguridad de $97.9 \%$ para US y de $84 \%$ para el examen físico al ser comparados con cirugía ${ }^{(23)}$.

A sus conocidas ventajas como método de imagen agrega la US la exploración fisiológica del paciente.

Para minimizar su dependencia del operador es necesario un buen conocimiento de los reparos anatómicos y una estandarización del examen que debe incluir la exploración en posición erecta y el uso de maniobras que aumenten la presión abdominal. Hay que tomar precauciones para no provocar aumento de presión con el transductor que pueda impedir la visualización de pequeñas hernias o hidroceles comunicantes.

En pacientes añosos con mayor riesgo de complicaciones quirúrgicas, la diferenciación de hernias directas e indirectas puede no ser menor. Algunos cirujanos proponen no operar las directas por su bajo riesgo de estrangulación. La US Doppler color permite plantear el diagnóstico diferencial al establecer la relación con los vasos epigástricos y así orientar a una conducta adecuada. Comparada con hallazgos quirúrgicos en pacientes adultos ha demostrado un valor predictivo positivo de $78 \%$ y un 
valor predictivo negativo de $89 \%$ para hernias directas, valores que para el examen físico son de $100 \%$ y $80 \%$ respectivamente ${ }^{(24)}$.

La identificación del contenido herniario y tipo de hernia previo a la cirugía puede permitir una mejor planificación de ella. El hidrocele y su relación con una hernia indirecta pueden también ser bien investigadas en niños.

En pacientes adultos deportistas de alta competencia y con dolores inguinales se ha descrito un tipo de hernia directa que se manifiesta a la US como un abultamiento de borde anterior convexo del contorno posterior de la pared de la región inguinal, con cambio de morfología del cordón espermático que se alarga en el plano craneocaudal(25).

En los casos de sexo ambiguo la US puede ayudar a la determinación de sexo, ya que permite una buena diferenciación entre testículo y ovario, demostrándose en este último la presencia de folículos normales en recién nacidos del sexo femenino por la estimulación hormonal materna.

Una masa inguinal indeterminada puede ubicarse en los distintos compartimentos con US y su caracterización permitirá una conducta terapéutica adecuada.

\section{Conclusión}

La disponibilidad de transductores lineales de alta resolución han permitido una adecuada exploración de la región inguinal la cual además puede ser efectuada en forma dinámica. El conocimiento de la anatomía y su representación permitirán un buen rendimiento del examen.

\section{Bibliografía}

1. Ekberg O. Inguinal herniography in adults: Technique, normal anatomy and diagnostic criteria for hernias. Radiology 1981; 138: 31-36.

2. Miltenburg D.M, Nuchtern J.G, Jaksic T. et al. Laparoscopic evaluation of the pediatric inguinal hernia - a meta-analysis. J Pediatr Surg 1998; 33: 874-879.

3. Van den Berg J.C, de Valois J.C, Go P.M. et al. Detection of groin hernia with physical examination, ultrasound and MRI compared with laparoscopic findings. Invest Radiol 1999; 34: 739-743.

4. Shadbolt C.L, Heinze S.B, Dietrich R.B. Imaging of groin masses: Inguinal anatomy and pathologic conditions revisited. Radiographics 2001; 21: S261-S271.

5. Testut $L$, LatarjetA. Tratado de anatomía humana. Salvat editores 1973. Pag 945-960.

6. Sadler T.W. Langman Embriología Médica con orientación clínica. $8^{\mathrm{a}}$ Ed. Editorial Panamericana. Buenos Aires. Argentina. 2001; Pag. 329.

7. Ballantyne A, Jawaheer G, Munro F.D. Contralateral groin exploration is not justified in infants with unilateral inguinal hernia. British Journal of Surgery 2001; 88: 720-723.

8. May E, O'Brien A, Liendo C., y col. Metalosis por titanio. Diagnóstico diferencial de masa del compartimento iliopsoas. Caso clínico. Rev Chil Radiol 2002; 8: 182184

9. Chou TY, Chu C.C, Diau GY. et al. Inguinal hernia in children: US versus exploratory surgery and intraoperative contralateral laparoscopy. Radiology 1996; 201: 385-388.

10. Wiener ES, Touloukian RJ, Rodgers B.M. et al. Hernia survey of the section on surgery of the American Academy of Pediatrics. J Pediatr Surg 1996; 31: 11661169.

11. Bock JE, Sobye JB. Frequency of contralateral inguinal hernia in children. Acta Chir Scand 1970; 136: 707-709.

12. Schneck F.K, Bellinger M.F. Abnormalities of the testis and scrotum and their surgical management. En Campbell's Urology Saunders Elsevier Science, USA. 8a Ed. 2002. Pag. 2553-2394.

13. Fenton L.Z, Mc Cabe K.J. Giant unilateral abdominoscrotal hidrocele. Pediatr Radiol 2002; 32: 882884.

14. Wallen E.M, Shortliffe L.M. Undescended testis and testicular tumors en Pediatric Surgery. $3^{\text {rd }}$ Ed. Ashcraft K.W. (editor). W.B. Saunders Company. 2000; Páginas 663-673.

15. Elder J.S. The undescended testis: Hormonal and surgical management. Surg Clin North Am 1988; 68: 983-1006.

16. Elder J.S. Ultrasonography is unnecessary in evaluating boys with a nonpalpable testis. Pediatrics 2002; 110: 748751.

17. Munden M, Mc Eniff N, Mulvihill D. Sonographic investigation of female infants with inguinal masses. Clin Radiol 1995; 50: 696-698.

18. Boley S.I, Cahn D, Lauer T. Et al. The irreductible ovary: A true emergency. J. Pediatr Surgery 1991; 26: 10351038.

19. Park S.J, Joo W.L, Young T.K. et al. Diagnosis of pelvic congestion syndrome using transabdominal and transvaginal sonography. AJR 2004; 182: 683-688.

20. Hodgkinson C.P. Phisiology of the ovaria veins during pregnancy. Obstet Gynecol 1953; 1: 26-37.

21. Weber T.R, Tracy Jr. TF. Groin hernias and hidroceles en Pediatric Surgery. Aschcraft K.W. editor. W B Saunders Philadelphia, Pa, $3^{\text {rd }}$ ed. 2000 Páginas 654673.

22. Erez I, Kovalivker M, Schneider N. et al. Elective sonographic evaluation of inguinal hernias in children. An effective alternative to routine contralateral exploration. Pediatr Surg 1993; 8: 415-418.

23. Chen KC, Chu CC, Chou TY. et al. Ultrasonography for inguinal hernias in boys. J Pediatr Surg 1998; 33: 17481787.

24. Korenkov M, Andreas P, Troidl H. Color duplex sonography: Diagnostic tool in the differentiation of inguinal hernias. J Ultrasound Med 1999; 18: 565-568.

25. Orchard J.W, Read J.W, Neophyton J, Garlick D. Groin pain associated with ultrasound finding of inguinal canal posterior wall deficiency in Australian Rules footballers. Br J Sports Med 1998; 32: 134-139. 